\title{
A fadiga muscular diminui a sensação de posição do ombro em andebolistas
}

\author{
Fernando Ribeiro ${ }^{1}$ \\ Gisela Gonçalves ${ }^{2}$ \\ João Venâncio 1,2 \\ José Oliveira ${ }^{1}$
}

https://doi.org/10.5628/rpcd.08.02.271

\author{
${ }^{1}$ Universidade do Porto \\ Faculdade de Desporto \\ Centro de Investigação em Actividade Física, \\ Saúde e Lazer \\ Portugal \\ ${ }^{2}$ Departamento de Fisioterapia \\ Escola Superior de Saúde de Vale do Sousa \\ Gandra \\ Portugal
}

\section{RESUMO}

Diversos estudos evidenciam que a fadiga muscular local diminui a propriocepção articular. Contudo, poucos estudos investigaram o efeito de protocolos funcionais, nos quais o exercício realizado se aproxima das exigências da actividade desportiva. O objectivo do presente estudo consistiu na avaliação, em andebolistas, do efeito da fadiga muscular local aguda induzida por exercício envolvendo a habilidade específica de remate em apoio na sensação de posição do ombro. A amostra foi constituída por 24 atletas do sexo masculino. A sensação de posição do ombro foi avaliada, antes e imediatamente após exercício, através da técnica de reposicionamento activo de uma posição passivamente determinada e foi reportada usando como indicadores o erro angular absoluto, o erro relativo, e o erro variável. $\mathrm{O}$ protocolo de exercício para induzir fadiga consistiu na execução de remates de sete metros, em apoio, à velocidade máxima. Os atletas terminavam o exercício quando reportavam um valor ?15 na Escala de Borg. Os atletas testados realizaram em média $59.96 \pm 12.97$ remates excedendo o valor $15(16.9 \pm 0.68) \mathrm{da}$ Escala de Borg. Após exercício, o erro angular absoluto aumentou $(2.53 \pm 1.10$ vs $3.46 \pm 1.64 ; \mathrm{p}=0.03)$ e diminuiu a fiabilidade das tentativas de reposicionamento, como o demonstra o aumento do erro variável em $37.7 \%$. Os resultados do presente estudo indicam que a fadiga muscular induzida por exercício envolvendo a habilidade específica de remate tem efeitos deletérios na sensação de posição do ombro de andebolistas.

\section{ABSTRACT \\ Skeletal-muscle fatigue decreases shoulder position sense in handball players}

Literature indicates that local muscle fatigue diminishes joint proprioception. However, few studies have been conducted investigating the effect of functional protocols, more close to the demands of the sport activity. The purpose of the present study was to assess the effect, in handball players, of exercise-induced acute muscle fatigue using a specific motor task, handball shot, on the shoulder joint position sense. The sample was composed by 24 male athletes. Shoulder position sense was evaluated, prior to and immediately after exercise using the technique of active positioning of a passively determined position, and was reported as absolute, relative and variable angular errors. The exercise protocol to induce fatigue consisted on repeated shots from a 7 meters distance to goal with maximum velocity. Athletes finished the exercise when a level ?15 on the Borg scale was reached. The athletes performed in average 59.96 \pm 12.97 shots, reaching or exceeding the scores of 15 $(16.9 \pm 0.68)$ on the Borg scale. After exercise, the absolute angular error increased $(2.53 \pm 1.10$ to $3.46 \pm 1.64 ; p=0.03)$ and the reliability in estimating shoulder angles decreased, as showed by the increase (37.7\%) in variable error. The results of the present study suggest that muscle fatigue induced by the specific motor task of handball shot has deleterious effects on shoulder joint position sense in handball players.

Key-words: joint position sense, local muscle fatigue, handball

Palavras-chave: sensação de posição articular, fadiga muscular local, andebol 


\section{INTRODUÇÃO}

O andebol é uma modalidade desportiva de esforço intermitente, caracterizada por acções de jogo de elevada intensidade, com contacto físico frequente, e a realização de habilidades usando o membro superior, de que são exemplos as fintas, passes e remates ${ }^{(1)}$. No andebol as lesões do complexo articular do ombro apresentam elevada incidência(2). Em habilidades motoras complexas, tal como o remate no andebol, o funcionamento adequado do sistema sensório-motor é essencial para a manutenção da integridade estrutural do complexo articular do ombro(3).

Tem sido sugerido que a elevada incidência de lesões desportivas que ocorrem no terço final da sessão de treino ou do jogo, está associada a défices no sistema sensório-motor, com diminuição do controlo neuromuscular e da estabilidade articular dinâmica, em consequência da fadiga ${ }^{(4)}$. Este efeito deletério da fadiga no sistema sensório-motor pode ser mediado por alteração na propriocepção $\operatorname{articular}^{(4)}$. A propriocepção pode ser definida como o input neural cumulativo para o sistema nervoso central proveniente de terminações nervosas especializadas denominadas de mecanoreceptores ${ }^{(5)}$. A propriocepção é comummente avaliada através de medidas da sensação de posição articular ou da sensação de movimento articular; a sensação de posição articular determina a capacidade de compreender um determinado ângulo articular e de, após a sua remoção, o reproduzir activa ou passivamente ${ }^{(6)}$. Vários estudos em diferentes contextos e núcleos articulares demonstraram que o exercício indutor de fadiga muscular diminui a sensação de posição articular(7-10). Contudo, nesses estudos, em geral a fadiga muscular foi induzida por exercício efectuado em dinamómetro isocinético, envolvendo articulações e grupos musculares isolados. Esse modo e forma de exercício não reproduz, no entanto, o contexto formal de diversas modalidades desportivas. Em atletas a utilização de protocolos funcionais, nos quais o exercício se aproxima ou reproduz as exigências da actividade desportiva, permite avaliar mais fielmente e com maior validade ecológica as alterações proprioceptivas e neuromusculares observadas em contextos formais de actividade desportiva. Desta forma, o objectivo do presente estudo foi avaliar, em andebolistas, o efeito da fadiga muscular local induzi- da por um protocolo funcional na sensação de posição do ombro.

\section{MATERIAL E MÉTODOS \\ Participantes}

A amostra foi constituída por 24 atletas (idade $=$ $21.96 \pm 1.71$ anos; peso $=78.4 \pm 11.4 \mathrm{~kg}$; altura $=$ $181.4 \pm 7.0 \mathrm{~cm}$ ) de andebol, de equipas que competem no Campeonato Nacional da $1^{\text {a }}$ e $2^{\text {a }}$ Divisão Portuguesa. Foram incluídos no estudo, atletas do sexo masculino sem história de lesão grave ou cirurgia no membro superior dominante. Dos 24 atletas que participaram no estudo, 12 apresentavam experiência competitiva entre 5 e 9 anos e os restantes $50 \%$ apresentavam experiência superior a 9 anos. Todos os sujeitos completaram a recolha de dados numa única sessão, no final da época desportiva, após familiarização com o protocolo experimental e com os instrumentos de avaliação. Foi testado o membro superior dominante, o direito na maioria dos atletas $(n=19)$. Todos os sujeitos deram o seu consentimento informado por escrito e todos os procedimentos foram efectuados de acordo com a declaração de Helsínquia.

\section{Avaliação da sensação de posição articular}

A avaliação da sensação de posição do ombro foi efectuada, antes e imediatamente após a aplicação do protocolo funcional indutor de fadiga muscular local, através da técnica de reposicionamento activo de uma posição passivamente determinada em cadeia cinética aberta. Foi investigada uma posição de rotação interna do ombro com reposicionamento activo efectuado (controlado) pelos rotadores externos em movimento a favor da gravidade. Os sujeitos estavam vendados e confortavelmente sentados no dinamómetro isocinético (Biodex System 3, NY, USA); a articulação do ombro do membro superior dominante foi posicionada a $90^{\circ}$ de abdução e rotação externa no plano da omoplata, o cotovelo foi colocado a $90^{\circ}$ de flexão e o antebraço em posição neutra (Figura 1). Esta posição foi escolhida porque permite que o reposicionamento se efectue com contracção excêntrica controlada dos músculos rotadores externos do ombro; músculos cuja contracção excêntrica durante o gesto técnico do remate é de extrema importância para a estabilidade dinâmica da articulação, para o 
controlo do movimento e para a diminuição do stress mecânico imposto aos elementos passivos de estabilização do ombro(11).

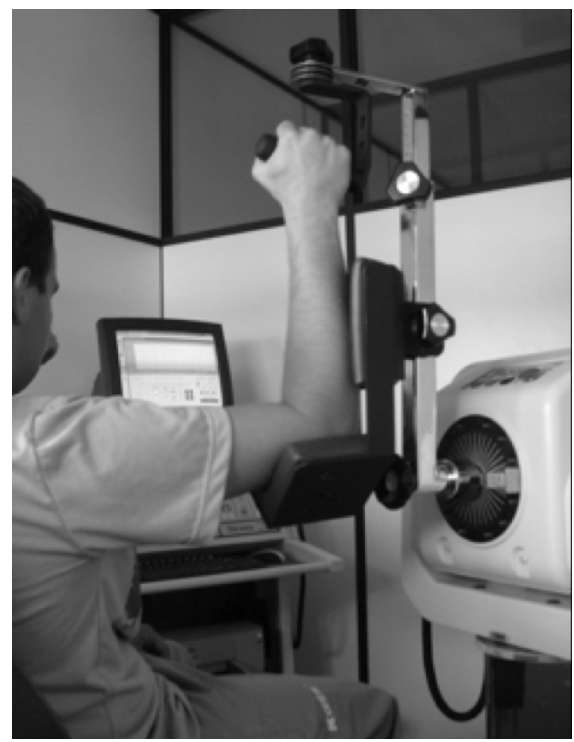

Figura 1. Posição inicial de avaliação da sensação de posição do ombro.

O examinador posicionava passivamente o ombro numa posição angular de rotação interna compreendida entre $30^{\circ}$ e $45^{\circ}$ a partir da posição inicial. O atleta mantinha essa posição activamente durante 5 segundos sem contacto manual por parte do examinador. Durante esse período, o atleta identificava a posição alvo. De seguida o examinador passivamente recolocava o membro superior na posição inicial. $\mathrm{O}$ atleta era então instruído a, ao comando "reposição", activamente reproduzir a posição alvo. Quando o atleta atingia a posição percebida como a posição alvo reportavam "alvo" e mantinham essa posição durante 3 segundos. Ao comando "regressar", o atleta regressava à posição inicial. Cada atleta realizou 3 tentativas tentando reproduzir a posição alvo de forma a obter uma amostra realista e consistente da sensação de posição articular para aquela posição alvo.

$\mathrm{O}$ valor angular da posição alvo e das 3 tentativas de reposicionamento foram registados com o goniómetro do dinamómetro isocinético (Biodex System 3, NY, USA). A sensação de posição articular é reportada neste estudo usando: (i) o erro angular absoluto, definido como a média da diferença absoluta entre a posição de teste e as 3 posições de reposicionamento; o erro absoluto contém a magnitude do erro e representa a capacidade geral de reprodução de determinado ângulo articular; (ii) o erro relativo, definido como a média da diferença aritmética sinalizada entre a posição de teste e as 3 posições de reposicionamento; a média do erro relativo após testes repetidos é uma medida de viés, representando a tendência para subestimar ou sobrestimar a posição de teste; e, (iii) o erro angular variável, definido como o desvio padrão do erro relativo, representando a fiabilidade das respostas de uma série de testes similares. No entanto, é necessário algum cuidado na interpretação dos valores isolados do erro relativo e variável, por exemplo: o erro relativo pode não detectar diferenças entre grupos de dados se a média dos valores não for significativamente diferente, e isso pode facilmente ocorrer se um grupo apresentar uma média maior que zero e o outro uma média similar mas negativa; o uso do erro de variação pode classificar a propriocepção de um sujeito como excelente desde que o erro seja consistente, ou seja, se este consistentemente errar no mesmo grau(12).

\section{Protocolo funcional indutor de fadiga muscular local} $O$ protocolo de fadiga consistiu na execução de remates de sete metros, em apoio. Foram utilizadas bolas e balizas com dimensões oficiais. Antes do protocolo foi efectuado um breve aquecimento, que incluiu alongamentos e remates, até o atleta se sentir confortável para efectuar remates à sua velocidade máxima. Durante o protocolo de fadiga os atletas foram instruídos a rematar de forma sequencial, para evitar que o atleta mantivesse a bola mais de 3 segundos na mão, à sua velocidade máxima até atingirem fadiga local.

Antes do protocolo de fadiga foram dadas instruções verbais e escritas sobre a Escala de Borg (escala de 6 a 20). A cada 20 remates cada atleta classificou o nível de esforço percebido localmente (extremidade superior) através da Escala de Borg. Os atletas foram considerados fatigados quando reportavam um valor de 15 ou superior; os atletas não foram informados deste limiar a partir do qual se terminava o protocolo. A Escala de Borg é uma medida válida da percepção da intensidade de esforço local do membro supe- 
rior( ${ }^{(13,14)}$. Para além disso, um valor de 15 na Escala de Borg apresenta uma elevada correlação com diversas alterações metabólicas associadas à fadiga muscular(15).

\section{Análise Estatística}

A análise estatística deste trabalho foi realizada utilizando o software para estatística SPSS versão 13.0. Para a descrição dos dados foram usados os valores da média e desvio padrão. Foi utilizado o teste de Shapiro-Wilk para testar a normalidade de distribuição dos dados. Para comparação de médias foi utilizado o teste-t emparelhado. O nível de significância foi estabelecido em $5 \%$.

\section{RESULTADOS}

Os atletas completaram o exercício de remate atingindo ou excedendo o valor 15 (média $\pm \mathrm{DP}=16,9 \pm$ 0,68; intervalo: 16-18) na Escala de Borg, após 59,96 $\pm 12,97$ remates.

Após exercício o erro angular absoluto aumentou significativamente (Quadro 1). Os valores médios do erro relativo indicam que em repouso e após exercício, os atletas subestimam a posição alvo, ou seja, sendo o movimento reproduzido pelos atletas o de rotação interna, verifica-se que estes marcam posições de menor rotação interna do que a posição alvo. A fadiga muscular local não exacerba significativamente, o erro relativo. No entanto, a consistência e precisão na estimação dos valores angulares do ombro diminui após o protocolo de fadiga, como o demonstra o aumento do erro angular variável em 37,7\%.

Quadro 1. Efeito do protocolo de fadiga na sensação de posição do ombro (em graus]

\begin{tabular}{lcc}
\hline & Repouso & Fadiga \\
\hline Erro Absoluto & $2,53 \pm 1,10$ & $3,46 \pm 1,64^{*}$ \\
\hline Erro Relativo & 1,00 & 1,58 \\
\hline Erro Variável & 2,52 & 3,47 \\
\hline
\end{tabular}

*diferença estatisticamente significativa para a condição de repouso; $p=0,03$

\section{DISCUSSÃO}

Que seja do nosso conhecimento o presente estudo é o primeiro a avaliar, em andebolistas, o efeito da fadiga muscular induzida por exercício repetido de uma habilidade motora específica na sensação de posição do ombro. Os resultados indicam que a sensação de posição do ombro do andebolista é menos precisa e menos consistente na presença de fadiga muscular local.

A observação de que a fadiga muscular local diminui a acuidade proprioceptiva, medida através da avaliação da sensação de posição e expressa pelo erro angular absoluto, vai de encontro aos resultados de estudos anteriores $(7,8,10,16,17)$ e suporta a teoria de "disfunção dos mecanoreceptores" proposta por Voight et al(17), que postula que a fadiga muscular dessensibiliza o fuso muscular e dessa forma diminui o feedback aferente ao sistema nervoso central. Os mecanoreceptores são neurónios sensoriais localizados no músculo, tendão, pele, ligamentos e cápsula articular ${ }^{(10,17)}$, que funcionam como conversores das cargas mecânicas impostas à articulação em impulsos aferentes, dando origem à informação proprioceptiva. Presentemente, existe consenso generalizado que a propriocepção é uma entidade complexa que engloba diversas modalidades, tais como a sensação de posição, de movimento e de força, e que o sinal aferente que dá origem a estas diferentes sensações tem origem, predominante, em diferentes tipos de receptores. A sensação de posição articular é sinalizada principalmente pelo fuso muscular, contudo a contribuição dos receptores cutâneos de adaptação lenta principalmente em movimentos multiarticulares não pode ser menosprezada ${ }^{(18-20)}$. Os protocolos de exercício intenso indutores de fadiga afectam, presumivelmente, o tecido muscular mais do que o tecido articular, e deste modo, a diminuição na sensação de posição articular pode conceptualmente ser secundária à diminuição ou perda de input dos receptores musculares. Se o fuso muscular desempenha um papel chave na construção da sensação de posição articular, e se a fadiga muscular local afecta preferencialmente os mecanoreceptores musculares, então, o efeito da fadiga local no fuso muscular pode representar um mecanismo plausível para os nossos resultados(7). A fadiga muscular local pode induzir disfunção do fuso muscular por aumento da concentração intramuscular de lactato, bradicinina, potássio e ácido araquidónico(16, 21, 22). Estas substâncias têm impacto directo no padrão de descarga do fuso muscular, aumentando o seu limiar e consequentemente alterando a co-activação alfa-gama(16, 21-23). 
A sinalização do fuso muscular é diferente da sinalização fornecida por outros receptores sensoriais. Para a maioria dos receptores, um aumento da taxa de descarga representa um aumento da intensidade do estímulo. Para o fuso muscular uma taxa de descarga elevada representa um músculo alongado (24). Desta forma, seria expectável que o erro relativo, que em repouso era positivo, se tivesse aproximado do zero ou eventualmente se tornasse negativo (sobrestimação da posição alvo); uma vez que a dessensibilização do fuso muscular ao alterar a sua capacidade de detectar de forma precisa o alongamento muscular, iria determinar a percepção de posições de alongamento menores do que a posição "real". Tal não se verificou. Este facto pode resultar do elevado erro de variação, que indica elevado ruído no sistema de processamento da informação, ruído esse proveniente dos sinais sensoriais enviados pelos mecanoreceptores. A variabilidade na performance numa tarefa de reposicionamento reflecte directamente o efeito desse ruído (25).

O sistema sensório-motor é responsável pela coordenação, percepção e feedback necessários para manter a estabilidade articular e o controlo da sequência de movimento na realização do remate, garantindo, dessa forma, a eficiência do movimento e prevenindo as lesões(26). Em atletas de modalidades que incluem frequentemente movimentos das extremidades superiores acima da cabeça, défices no sistema sensóriomotor podem induzir incapacidade para apreciar e manter a estabilidade articular e o controlo e coordenação que devem estar presentes no desempenho de habilidades e acções motoras complexas, como é o caso do remate no andebol. Tais défices podem resultar em sobrecarga excessiva das estruturas articulares e peri-articulares e contribuir para a elevado número de lesões no ombro que se observada em andebolistas (2). A integração da fadiga no modelo de estabilidade funcional $(26,27)$ suporta a ideia de que $o$ gesto técnico repetido conduz à alteração da homeostasia e função muscular, induzindo adicionalmente défices aferentes (proprioceptivos) e eferentes, que se manifestam pela diminuição do controlo neuromuscular e instabilidade articular, diminuição da performance e aumento do risco de lesão. As implicações práticas da diminuição da sensação de posição do ombro induzida pelo gesto técnico repetido indutor de fadiga local para os profissionais das áreas das ciências do desporto e da saúde situam-se a dois níveis: prevenção/reabilitação de lesões e performance desportiva. Primeiro, a informação proprioceptiva aferente adequada permite respostas neuromusculares eferentes também elas adequadas, sejam elas pré-programadas ou reflexas, preservando a estabilidade articular e contribuindo para a prevenção de lesões. Segundo, foi demonstrado que a força muscular produzida pelos músculos motores do complexo articular do ombro é alterada significativamente pela alteração da posição articular de um dos seus componentes(28). Desta forma é perfeitamente plausível que a diminuição da acuidade para determinar a posição do ombro no espaço possa induzir diminuição da performance desportiva do andebolista. $\mathrm{O}$ reconhecimento de que a fadiga pode diminuir a capacidade de percepcionar posições articulares de maior vulnerabilidade, levanta a necessidade de incluir exercícios de resistência muscular, principalmente nos músculos estabilizadores do complexo articular do ombro, de forma a preservar a acuidade proprioceptiva.

O presente estudo apresenta limitações a considerar em futuros estudos: as implicações práticas decorrentes deste estudo estão limitadas a andebolistas do sexo masculino sem história de lesão grave ou cirurgia no membro superior; tal como qualquer protocolo estandardizado, o protocolo usado neste estudo não reflecte a totalidade da realidade competitiva, sendo o remate em apoio apenas uma das componentes do jogo; apesar de ter sido pedido aos atletas para rematarem com o máximo de velocidade, não se mediu a velocidade da bola; da mesma forma, o posicionamento dos atletas testados e o movimento realizado no dinamómetro não reproduzem fielmente a habilidade do remate em andebol. Futuros estudos devem medir a velocidade da bola e desta forma avaliar, mesmo que indirectamente, a fadiga muscular local. Em futuros trabalhos a avaliação multi-articular da sensação de posição do membro inferior na habilidade do remate deverá ser privilegiada, de forma a tentar reproduzir as acções habitualmente ligadas ao contexto formal da actividade desportiva. Em conclusão, este estudo demonstrou que a fadiga muscular local induzida por um protocolo funcional tem efeitos deletérios na sensação de posição do ombro em atletas de andebol. 


\section{CORRESPONDÊNCIA}

\section{Fernando Ribeiro}

Universidade do Porto, Faculdade de Desporto

Centro de Investigação em Actividade Física,

Saúde e Lazer

Rua Dr. Plácido Costa, 91 - 4200-450 Porto

Portugal

E-mail: fernando.silva.ribeiro@gmail.com

\section{REFERÊNCIAS}

1. Langevoort G, Myklebust G, Dvorak J, Junge A (2007). Handball injuries during major international tournaments. Scand J Med Sci Sports 17(4): 400-407

2. Seil R, Rupp S, Tempelhof S, Kohn D (1998). Sports injuries in team handball. A one-year prospective study of sixteen men's senior teams of a superior nonprofessional level. Am J Sports Med 26(5): 681-687

3. Lephart SM, Pincivero DM, Giraldo JL, Fu FH (1997). The role of proprioception in the management and rehabilitation of athletic injuries. Am J Sports Med 25(1): 130-137

4. Hiemstra LA, Lo IK, Fowler PJ (2001). Effect of fatigue on knee proprioception: implications for dynamic stabilization. J Orthop Sports Phys Ther 31(10): 598-605

5. Ribeiro F, Oliveira J (2007). Aging effects on joint proprioception: the role of physical activity in proprioception preservation. Eur Rev Aging Phys Act 4: 71-76

6. Rozzi S, Yuktananandan P, Pincevero D, Lephart SM (2000). Role of Fatigue on Proprioception and Neuromuscular Control. In: Lephart SM, Fu FH (ed). Proprioception and Neuromuscular Control in Joint Stability. Champaign, IL: Human Kinetics, 375-384

7. Ribeiro F, Mota J, Oliveira J (2007). Effect of exercise-induced fatigue on position sense of the knee in the elderly. Eur J Appl Physiol 99(4): 379-385

8. Lee HM, Liau JJ, Cheng CK, Tan CM, Shih JT (2003). Evaluation of shoulder proprioception following muscle fatigue. Clin Biomech (Bristol, Avon) 18(9): 843-847

9. Bjorklund M, Crenshaw AG, Djupsjobacka M, Johansson H (2000). Position sense acuity is diminished following repetitive low-intensity work to fatigue in a simulated occupational setting. Eur J Appl Physiol 81(5): 361-367

10. Carpenter JE, Blasier RB, Pellizzon GG (1998). The effects of muscle fatigue on shoulder joint position sense. Am J Sports Med 26(2): 262-265

11. Pezarat Correia P (2004). Padrões de coordenação neuromuscular associados ao movimento do braço e antebraço em acções e lançamento: contributos para a orientação do treino de força. Conexões 2(2): 1-17

12. Beynnon BD, Ryder SH, Konradsen L, Johnson RJ, Johnson K, Renstrom PA (1999). The effect of anterior cruciate ligament trauma and bracing on knee proprioception. Am J Sports Med 27(2): 150-155

13. Kang J, Chaloupka EC, Mastrangelo MA, Donnelly MS, Martz WP, Robertson RJ (1998). Regulating exercise intensity using ratings of perceived exertion during arm and leg ergometry. Eur J Appl Physiol Occup Physiol 78(3): 241-246

14. Marais G, Weissland T, Robin H, Vanvelcenaher JM, Lavoie JM, Pelayo P (1999). Physiological effects of variations in spontaneously chosen crank rate during sub-maximal and supra-maximal upper body exercises. Int J Sports Med 20(4): 239-245

15. Edwards RH, Melcher A, Hesser CM, Wigertz O, Ekelund LG (1972). Physiological correlates of perceived exertion in continuous and intermittent exercise with the same average power output. Eur J Clin Invest 2(2): 108-114

16. Pedersen J, Lonn J, Hellstrom F, Djupsjobacka M, Johansson H (1999). Localized muscle fatigue decreases the acuity of the movement sense in the human shoulder. Med Sci Sports Exerc 31(7): 1047-1052

17. Voight ML, Hardin JA, Blackburn TA, Tippett S, Canner GC (1996). The effects of muscle fatigue on and the relationship of arm dominance to shoulder proprioception. $J$ Orthop Sports Phys Ther 23(6): 348-352

18. Proske U (2005). What is the role of muscle receptors in proprioception? Muscle Nerve 31(6): 780-787

19. Proske U, Wise AK, Gregory JE (2000). The role of muscle receptors in the detection of movements. Prog Neurobiol 60(1): 85-96

20. McCloskey DI (1978). Kinesthetic sensibility. Physiol Rev 58(4): 763-820

21. Djupsjobacka M, Johansson H, Bergenheim M, Wenngren BI (1995). Influences on the gamma-muscle spindle system from muscle afferents stimulated by increased intramuscular concentrations of bradykinin and 5-HT. Neurosci Res 22(3): 325-333

22. Djupsjobacka M, Johansson H, Bergenheim M, Sjolander P (1995). Influences on the gamma-muscle-spindle system from contralateral muscle afferents stimulated by $\mathrm{KCl}$ and lactic acid. Neurosci Res 21(4): 301-309

23. Pedersen J, Sjolander P, Wenngren BI, Johansson H (1997). Increased intramuscular concentration of bradykinin increases the static fusimotor drive to muscle spindles in neck muscles of the cat. Pain 70(1): 83-91

24. Proske U (2006). Kinesthesia: the role of muscle receptors. Muscle Nerve 34(5): 545-558

25. van Beers RJ, Sittig AC, Denier van der Gon JJ (1998). The precision of proprioceptive position sense. Exp Brain Res 122(4): 367-377

26. Lephart SM, Fu FH (2000). Proprioception and Neuromuscular Control in Joint Stability. Champaign, IL: Human Kinetics.

27. Tripp BL, Yochem EM, Uhl TL (2007). Functional fatigue and upper extremity sensorimotor system acuity in baseball athletes. J Athl Train 42(1): 90-98

28. Sousa O, Ribeiro F, Leite M, Silva F, Azevedo AP (2007). Efeito da posição da omoplata na força máxima isométrica de flexão do ombro. Rev Port Cien Desp 7(2): 183-188 